\title{
Influence of Physicochemical Properties on Ball-Milling of Pharmaceutical Powders
}

\author{
Akiko Ikekawa, Kanji Imagawa, Toshie Omori, \\ and Nobuyoshi Kaneniwa \\ School of Pharmaceutical Sciences, Showa University1)
}

(Received February 4, 1971)

\begin{abstract}
Ball-milling of thirty-two kinds of powders were investigated. Equation (1) was applied for rate of increase of surface area.

$d S / d t=\mathrm{k}_{1} \exp \left(-\mathrm{k}_{2} S\right)$

(1)

Parameter $k_{1}$ was proportional to $1 /$ Mohrs'es hardness and tended to be small for the samples with high melting point. Rarameter $\mathbf{k}_{2}$ was small for the sample with high melting point and little solubility in water.

Critical particle size, $D_{\mathrm{C}_{2}}$, was found at which maximum porosity in loosest packing was obtained not only for crushed samples but for samples of equal particle size. For particles below $D_{c_{2}}$, gravitational force of a particle may be negligibly small compared with cohesive force between particles. $D_{\min }$ was proportional to $D_{c_{2}}$. Parameter $k_{1}$ tended to decrease and $\mathrm{k}_{2}$ to increase with increase of $\rho \cdot D_{\mathrm{min}}$. Rate of increase of surface area by ball-milling is considered to depend on coherency of powder particles expressed as a function of surface energy, melting point, solubility in water, true density and so on.
\end{abstract}

As reported in the previous papers, mean particle size and particle size distribution influence remarkably on physical properties of groups of powder particles. ${ }^{2-5}$ ) Ability of dispersion and coherency of powder particles affect largely on pharmaceutical procedures, such as tablet compression. "Particle size" is also one of the important parameters concerning pharmaceutical problems, such as medical effect, durability of medicines and stability of suspensions.

It is important and necessary to establish a method of getting samples of desirable particle size and distribution. Many workers reported on milling practically used as one of the methods of getting powders, ${ }^{6}$ ) but detailed mechanism of milling has not clarified yet.

In this work, influence of physical and chemical properties of samples on rate of increase of surface area by ball-milling was investigated, in order to make clear the mechanism of ball-milling.

\section{Experimental}

The ball-milled samples are tabullated in Table I.

$V \mathrm{~cm}^{3}$ of a sample, shown by true volume, was inserted in a ceramic mill, $8 \mathrm{~cm}$ in diameter and $450 \mathrm{ml}$ in capacity. The mill was revolved with the rate of $147 \mathrm{rpm}$, containing twenty ceramic balls with true density of 2.4 , of which five were $2.5 \mathrm{~cm}$ in diameter and fifteen were $1.9 \mathrm{~cm}$ in diameter.

1) Location: Hatanodai, Shinagawa-ku, Tokyo.

2) N. Kaneniwa, A. Ikekawa, and H. Aoki, Chem. Pharm. Bull. (Tokyo), 15, 1441 (1967); A. Ikekawa, H. Aoki; K. Masukawa, and N. Kaneniwa, ibid., 15, 1626 (1967); A. Ikekawa and N. Kaneniwa, ibid., 16, 1174, 1543 (1968); N. Kaneniwa and A. Ikekawa, ibid., 16, 1433 (1968); N. Kaneniwa and A. Ikekawa, Yakuzaigaku, 28, 35 (1968).

.3) N. Kaneniwa and A. Ikekawa, Yakuzaigaku., 27, 245 (1967).

4) N. Kaneniwa, A. Ikekawa, T. Ozaki, C. Shinya, N. Sugimoto, and Y. Hozumi, Yakugaku Zasshi, 88,1642 (1968).

5) A. Ikekawa, and N. Kaneniwa, Chem. Pharm. Bull. (Tokyo), 17, 827 (1969).

6) T. Tanaka "Huntai Kogaku Handbook," Asakura Shoten, 1965, p. 333; T. Tanaka and A. Suzuki, “Huntai no Bussei to Kogaku, Kagaku Zokan," No. 31, 1967, p. 147. 
TABLE I

\begin{tabular}{|c|c|c|c|c|c|c|c|}
\hline \multicolumn{2}{|r|}{ Sample } & \multirow{2}{*}{$\frac{\rho}{3.90}$} & \multirow{2}{*}{$\frac{V\left(\mathrm{~cm}^{3}\right)}{12.8}$} & \multicolumn{2}{|r|}{ Sample } & \multirow{2}{*}{$\frac{\rho}{1.50}$} & \multirow{2}{*}{$\frac{V\left(\mathrm{~cm}^{3}\right)}{20.0}$} \\
\hline 1 & White alundum & & & 17 & Sulfamethoxypyridazine & & \\
\hline 2 & Glass beads & 2.46 & 20.3 & 18 & Sulfamonomethoxyn & 1.52 & 26.4 \\
\hline 3 & Talc & 3.04 & 10.5 & 19 & Homosulfamine & 1.53 & 26.2 \\
\hline 4 & Sulfur & 2.04 & 29.4 & 20 & Sulfadimethoxyn & 1.46 & 34.2 \\
\hline 5 & Silica sand & 2.65 & 26.9 & 21 & Acetyl-salicylic acid & 1.41 & 42.6 \\
\hline 6 & Cupric sulfate & 2.29 & 26.2 & 22 & Ethyl $p$-amino-benzoate & 1.19 & 50.4 \\
\hline 7 & Sodium thiosulfate & 1.72 & 33.2 & 23 & Antipyrine & 1.27 & 39.4 \\
\hline 8 & Potassium chloride & 1.99 & 25.2 & 24 & Acetanilide & 1.22 & 40.9 \\
\hline 9 & Potassium nitrate & 2.11 & 23.7 & 25 & Lactose & 1.47 & 34.0 \\
\hline 10 & Potassium sulfate & 2.66 & 22.5 & 26 & Acacia powder & 1.53 & 32.7 \\
\hline 11 & Boric acid & 1.45 & 13.8 & 27 & $\mathrm{D}(+)$-Glucose anhydrous & 1.54 & 32.4 \\
\hline 12 & Sodium borate & 1.73 & 28.9 & 28 & DL-Tartaric acid & 1.76 & 28.4 \\
\hline 13 & Sodium bicarbonate & 2.21 & 27.2 & 29 & Oxalic acid & 1.90 & 26.2 \\
\hline 14 & Calcium chloride dihydrate & 1.80 & 33.3 & 30 & Zinc acetate & 1.75 & 28.7 \\
\hline 15 & Sulfaphenazol & 1.43 & 21.0 & 31 & Tri-potassium citrate & 2.06 & 19.4 \\
\hline 16 & Sulfisomidine & 1.42 & 21.0 & 32 & Potassium tartrate & 1.98 & 20.1 \\
\hline
\end{tabular}

$V$; true volume of a sample inserted in a mill

Surface area was measured by air permeability method, ${ }^{7)}$ porosity in loosest packing by JIS standard funnel method8) and true density in nitrogen with 930 Type Toshiba-Beckmann Air Comparison Pycnometer. Five grams of a sample in loosest packing in a cylinder, $1 \mathrm{~cm}$ in diameter and $25 \mathrm{ml}$ in capacity, was tapped once a second from the height of $1 \mathrm{~cm}$.

\section{Result and Discussion}

As shown in Fig. 1, rate of increase of surface area was decreased gradually with the lapse of ball-milling time and reached approximately zero, where the value of minimum particle diameter, $D_{\min }$ (specific surface diameter), or that of maximum surface area, $S_{\infty}$, was ob-

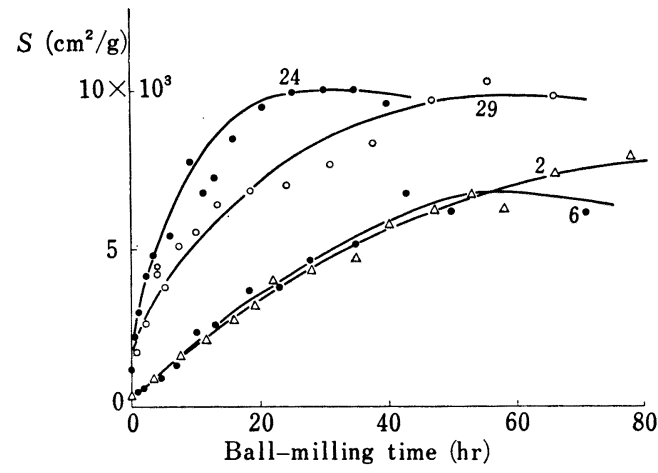

Fig. 1. Relation between Surface Area of Powders and Ball-Milling Time

numbering: See Table I.

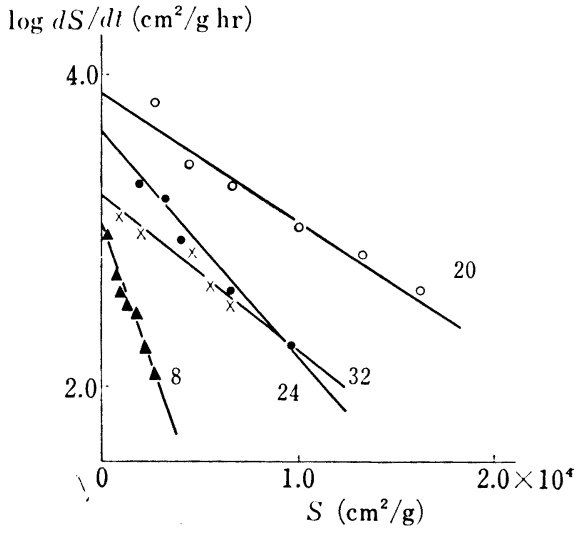

Fig. 2. Rate of Increase of Surface Area by Ball-Milling

numbering: See Table I.

7) E. Suito, M. Arakawa, and M. Takahashi, Kogyo Kagaku Zasshi, 59, 307 (1956).

8) JIS Z 2502-1958. 
tained. Equation (1) was applied as shown in Fig. 2, where $S$ was specific surface area of a sample.9)

$$
d S / d t=\mathrm{k}_{1} \exp \left(-\mathrm{k}_{2} S\right)
$$

Parameter $\mathrm{k}_{1}$ is identical with $d S / d t$ for the sample with diameter large enough for the surface area to be ignored. Parameter $\mathrm{k}_{\mathbf{2}}$ is related to decrease of $d S / d t$ probably due to coherency of particles caused by increase of surface area by ball-milling.

Fig. 3 shows the influence of inserted volume, $V$, of a sample on $\mathrm{k}_{1}, \mathrm{k}_{2}$, and $D_{\min }$. Parameter $\mathrm{k}_{1}$ was proportional to $V^{-\mathbf{1 . 6}}$, but $\mathrm{k}_{2}$ was independent of $V$ and dependency of $D_{\min }$ on $V$ was little. In this work, these results were assumed to be applied to all the samples in Table I.

Linear relation was obtained by logarithmic plot of $k_{1} V^{1.6}$ versus $1 /$ Mohrs'es hardness. (Fig. 4) In Fig. 5, $\mathrm{k}_{1} V^{\mathbf{1 . 6}}$ was plotted versus the smallest among melting, decomposition and transformation point. Hereafter, "melting point" means the smallest of the three. Generally, $\mathrm{k}_{1} V^{\mathbf{1 . 6}}$ was small for the sample of high melting point. Reversed tendency for organic powders with melting point below $130^{\circ}$ and inorganic powders with that below $70^{\circ}$ is probably due to melting of a part of samples by partial rising of temperature by impact stress of balls. Benson, et al. reported that Mohrs'es hardness was pararrel to surface energy of a solid. ${ }^{10)}$ Melting point is considered to rise with increase of cohesive force between molecules, that is, surface energy of solid. From the above facts $k_{1}$ is suggested to be small for the sample with large surface energy.

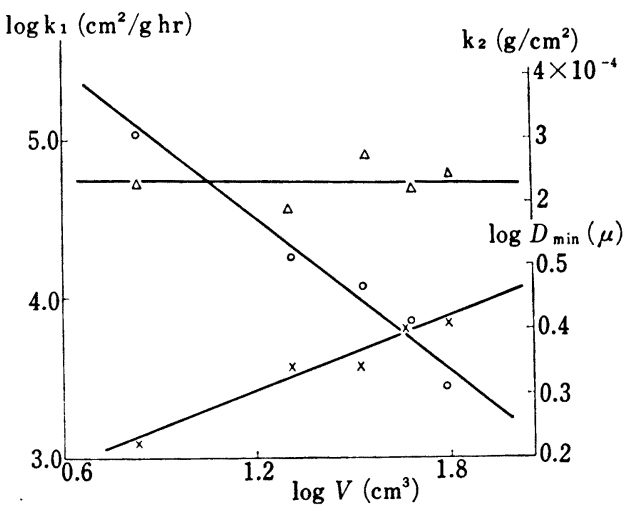

Fig. 3. Influence of True Volume of Inserted Powders on Parameter $\mathrm{k}_{1}, \mathrm{k}_{2}$ and $D_{\min }$ for Ball-Milling of Sulfadimethoxyn

$$
k_{1}: \bigcirc \quad k_{2}: \triangle \quad D_{\min }: \times
$$

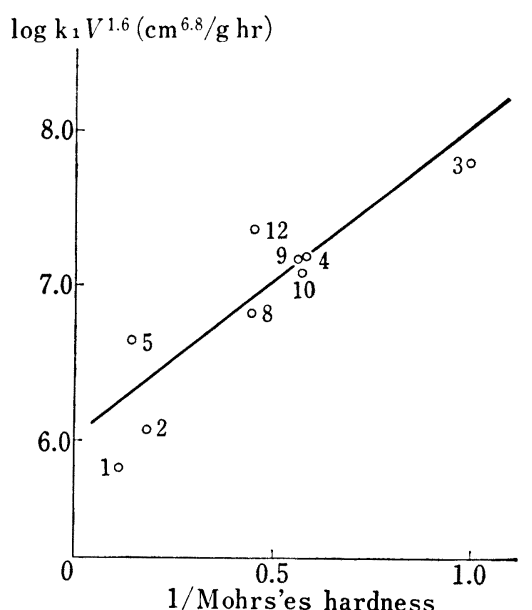

Fig. 4. Relation between Parameter $\mathbf{k}_{\mathbf{1}}$ and Mohrs'es Hardness

numbering: See Table I.

Mohrs'es hardness of No. 8 and No. 10 are supposed to be equal to those of sodium chloride and sodium sulfate hydrated, respectively.

Remarkably large values were obtained for $D_{\min }$ of the organic powders with melting point below $130^{\circ}$ or with high molecular weight and inorganic powders with melting point below $70^{\circ}$ or with high absorption power of moisture.9) For organic powders with high melting

9) N. Kaneniwa and A. Ikakawa, Yakuzaigaku, in press.

10) G.C. Benson and G.W. Benson, Can. J. Chem., 33, 233 (1955). 


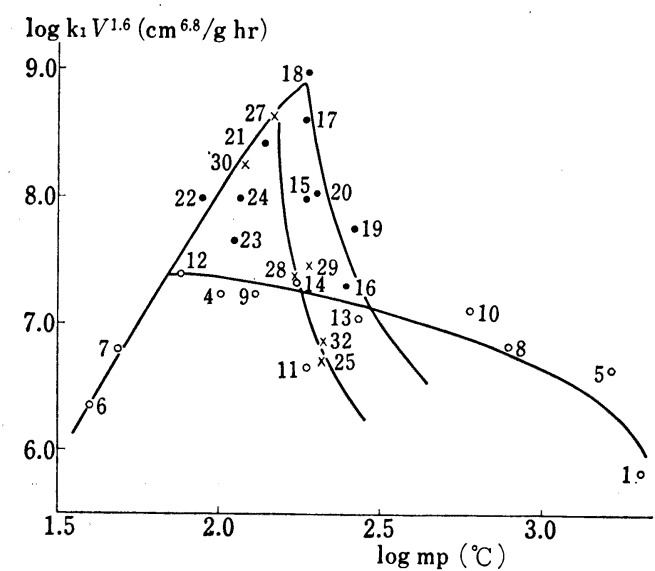

Fig. 5. Influence of Melting (Decomposition or Transformation) Point on Parameter $\mathrm{k}_{1}$

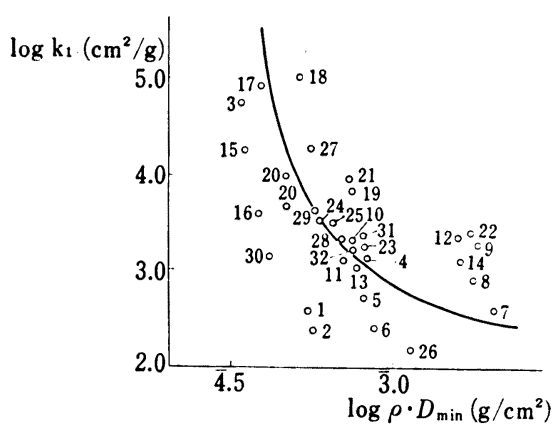

Fig. 6. Relation between $\mathrm{k}_{1}$ and $\rho \cdot D_{\min }$ numbering: See Table I.

point, $D_{\min }$ seemed to increase slightly with the rise of melting point. As shown in Fig. 6, $\mathrm{k}_{1}$ tended to decrease with increase of $\rho \cdot D_{\min }$. Large value of $S_{\infty}$ or small value of $D_{\min }$ was suggested to be obtained for the sample with small surface energy.

For organic powders with melting point above $140^{\circ}, \mathrm{k}_{2}$ was small for the sample with high melting point (see Fig. 7). Influence of partial melting on $d S / d t$ may become more remarkable as surface area increases, and probably this effect is more remarkable for the sample with low melting point. Clear tendency was not obtained between $\mathrm{k}_{2}$ and melting point for inorganic powders, probably because of high absorption power of moisture of some samples. But $\mathrm{k}_{2}$ was small for inorganic samples with high melting point and little solubility in water. Excepting the samples with low melting point or high solubility in water, $\mathrm{k}_{\mathbf{2}}$ seemed to be large for the sample with large value of $\rho \cdot D_{\min }$.

Rate of increase of surface area by ball-milling is considered to be large for large value of $k_{1}$ and small value of $k_{2}$. The numerical values of $\left(\log k_{1}\right) / k_{2}$ tended to be large for small value of $\rho \cdot D_{\min }$ (see Fig. 8).

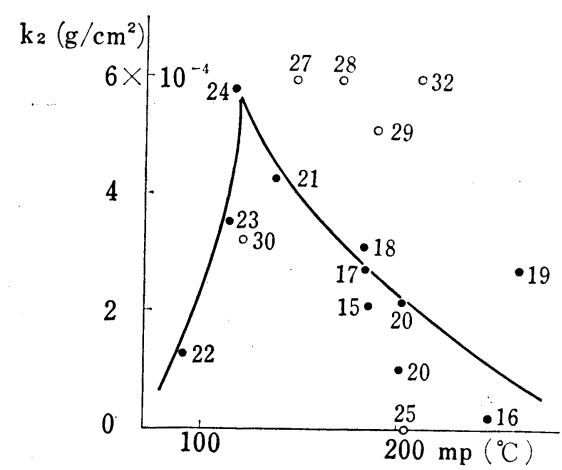

Fig. 7. Influence of Melting (Decomposition or Transformation) Point on Parameter $\mathrm{k}_{\mathbf{2}}$ for Organic Powders

: aromatic $\bigcirc$ : non-aromatic numbering: See Table I.

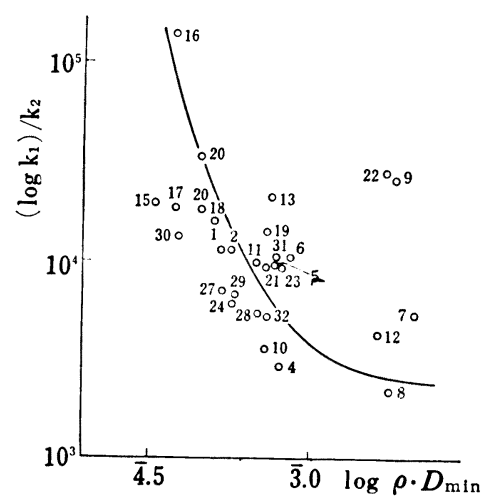

Fig. 8. Relation between $\left(\log k_{1}\right) / k_{2}$ and $\rho \cdot D_{\min }$ numbering: See Table I. 
Rittinger proposed equation (2) as a comminution law, ${ }^{11)}$ and Tanaka proposed equation (3) on the basis of consideration of the existence of limit for milling, ${ }^{12)}$ where $E$ was the energy added to a sample.

$$
\begin{aligned}
d S / d E & =K_{\mathrm{r}} \\
K_{\mathrm{r}} & : \text { constant } \\
d S / d E & =K_{\mathrm{t}}\left(S_{\infty}-S\right) \\
K_{\mathrm{t}} & : \text { constant }
\end{aligned}
$$

Here the energy added to a sample per unit time, $d E / d t$, was assumed to be constant. Equation (1) is identical with equation (2), if $k_{2}$ is equal to zero or numerical value of $S$ is negligibly small. Equation (1) is represented as equation (4), if $\mathrm{k}_{2} S$ is remarkably small compared with one.

$$
d S / d t=\mathrm{k}_{1} \mathrm{k}_{2}\left(1 / \mathrm{k}_{2}-S\right)
$$

Equation (4) is identical with equation (3), if $K_{t}$ is equal to $\mathrm{k}_{\mathbf{1}} \cdot \mathrm{k}_{\mathbf{2}}$, and $S_{\infty}$ to $1 / \mathrm{k}_{\mathbf{2}}$. Equation (3) was applied for the first step of ball-milling and mutual relation was obtained between $K_{t}$ and $\mathrm{k}_{1} \cdot \mathrm{k}_{2}$, as shown in Fig. 9 .

Chujo proposed equation (5), by evolving Rosin-Rammler's law of particle size distribution for crushed samples, where $R$ was cumulative oversize, $x$ was particle size and $b$ and $n_{r}$ were constants.

$$
R=\exp \left(-b E x^{n r}\right) \quad(5)^{13,14)}
$$

For sphere particles, equation (6) can be applied for the relation between surface area and particle size distribution, where $x_{1}$ is the size of the smallest particle and $x_{2}$ is the size of the largest one.

$$
S=(6 / \rho) b E \int_{x_{1}}^{x_{2}}(1 / x) \cdot \exp \left(-b E x^{n_{\mathrm{r}}}\right) d x
$$

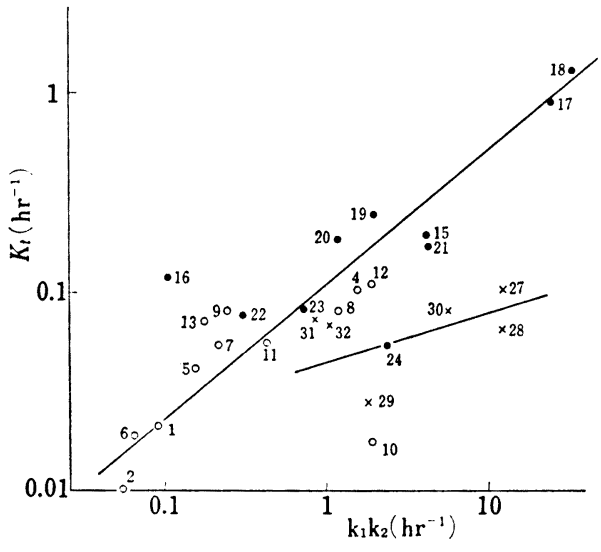

Fig. 9. Mutual Relation between $K_{\mathrm{t}}$ and $\mathbf{k}_{\mathbf{1}} \mathbf{k}_{\mathbf{2}}$ $\mathrm{O}$ : inorganic powders
$x:$ non-aromatic organic powders numbering: See Table I.

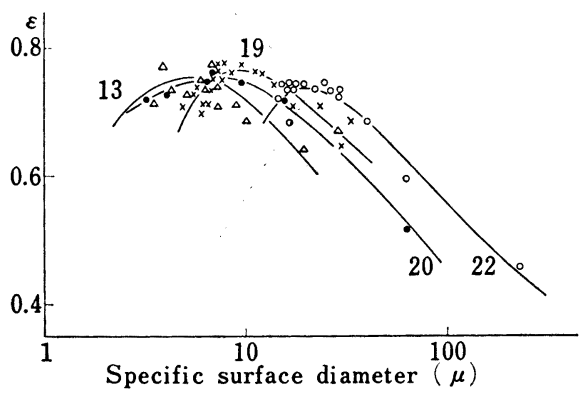

Fig. 10. Relation between Specific Surface Diameter and Porosity in Loosest Packing of Crushed Powders

11) U. Nakagawa: "Funtai," 3 rd ed. by K. Kubo, E. Suito, U. Nakagama and S. Hayakawa, Maruzen, 1964, p. 5.

12) T. Tanaka, Kagaku Kogaku, 18, 160 (1954).

13) K. Chujo, Kagaku Kogaku to Kagaku Kikai, 7, 1 (1949).

14) P. Rosin and E. Rammler, J. Inst. Fuel., 7, 29 (1923). 
Tanaka showed that $d S / d E$ was represented by equation (7), if $n_{\mathrm{r}}$ was equal to one, and $x_{2}$, nearly $100 \mu$, was much larger than $x_{1}{ }^{12}$ )

$$
d S / d E \doteqdot(6 / \rho) b \ln \left(x_{2} / x_{1}\right)\left[1-\left\{1 / \ln \left(x_{2} / x_{1}\right)\right\} \sum_{n=1}^{\infty}(-1)^{n-1}(1+1 / n)\left(b E x_{2}\right) n / n !\right]
$$

Equation (8) is a polynominal expression of equation (1).

$$
d S / d t=\mathrm{k}_{1}\left\{1-\sum_{n=1}^{\infty}(-1)^{n}\left(\mathrm{k}_{2} S\right) n / n !\right\}
$$

As $x_{2} / x_{1}$ is regarded as constant, it seems to be reasonable that proper expression of rate of increase of surface area by ball-milling is the type as equation (1).

Change of porosity was observed as surface area increased and maximum porosity was obtained for a certain particle size, $D_{\mathrm{c} 2}$ (specific surface diameter) (see Fig. 10). In the previous paper, angle of repose of white alundum of equal size was investigated and maximum angle was obtained for the sample of approximately $4 \mu{ }^{4)}$ Furthermore Kaneniwa, et al. found a critical size nearly at $4 \mu$ for packing of binary mixture of white alundum of equal size. ${ }^{15}$ ) Now loosest packing and close packing by tapping were investigated for white alundum of equal particle size. As shown in Fig. 11, critical size was found nearly at $3 \mu$, where maximum porosity in loosest state and minimum parameter, $b(1-a) / a$, of Kawakita's tapping equation $(9)^{\mathbf{3}, 16)}$ were obtained.

$$
\begin{aligned}
& -d \varepsilon_{\mathrm{n}} / / d n=b(1-a) / a \cdot \varepsilon_{\mathrm{n}}^{2} \\
& \varepsilon_{\mathrm{n}}: \text { porosity of a sample after } \mathrm{n} \text { tappings }
\end{aligned}
$$

The numerical value of $D_{\mathrm{c} 2}, 3.7 \mu$, obtained for maximum porosity of crushed white alundum is identical with those of the critical size mentioned above. For the case of crushed sulfa

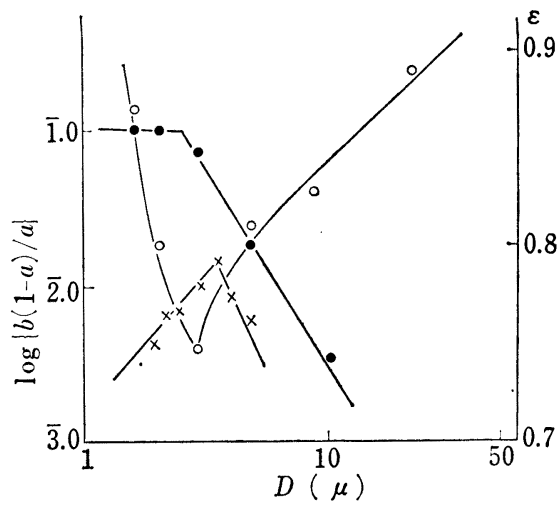

Fig. 11. Influence of Particle Size on Porosity in Loosest Packing and Kawakita's Tapping Parameter for White Alundum

$\bigcirc:$ Kawakita's tapping parameter

: porosity of the sample of equal particle size in loosest packing

$x:$ porosity of the ball-milled sample in loosest packing

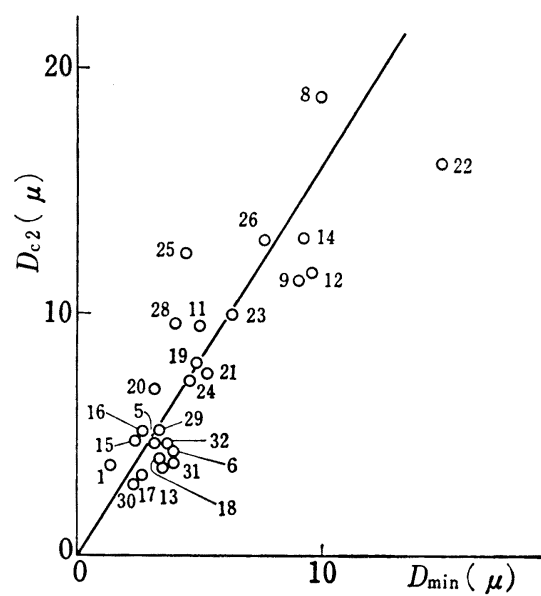

Fig. 12. Relation between $D_{\mathrm{c}_{2}}$ and $D_{\min }$ numbering: See Table I.

15) N. Kaneniwa and S. Eda, Funtai Kogaku Kenkyu Kaishi, 7, 168 (1970).

16) K. Kawakita, Takamine Kenkyujo Nenpo, 8, 83 (1956); S. Taneya and T. Sone, Oyo Butsuri, 31, 483 (1962); T. Morioka, Y. Ikegami and E. Nakajima, Yakuzaigaku, 19, 119 (1959); K. Kawakita and Y. Tsutsumi, Zairyo, 14, 11 (1965). 
dimethoxyn, nearly equal value of $D_{\mathrm{c} 2}, 6.9 \mu$, was also obtained for maximum value of porosity and minimum value of Kawakita's tapping parameter. In the previous papers, ${ }^{2)}$ another critical particle size, $D_{\mathrm{c} 1}$, was found approximately at $100 \mu$, below which physical properties of groups of powder particles of sodium borate and boric acid changed remarkably with decrease of particle size, and $D_{\mathrm{c} 1}$ was considered to be the size below which cohesive force between powder particles could not be ignored against gravitational force of a powder particle. For particles below $D_{\mathrm{c} 2}$, gravitational force of a powder particle may be negligibly small compared with cohesive force between particles. Particles below $D_{\text {c2 }}$ probably cohere each other, which causes change in physical properties of groups of particles.

As shown in Fig. 12, a straight line going through origin was obtained by plotting $D_{\mathrm{c} 2}$ versus $D_{\mathrm{min}}$. On the basis of the above findings, $d S / d t$ is considered to be dependent on coherency of samples. The tendency of small decrease of $D_{\min }$ with increase of true density of a sample was also obtained, with exception of the samples with low melting point, high molecular weight or high solubility in water.9) Coherency of powder particles is dependent on surface energy, solubility in water, melting point and true density of samples.

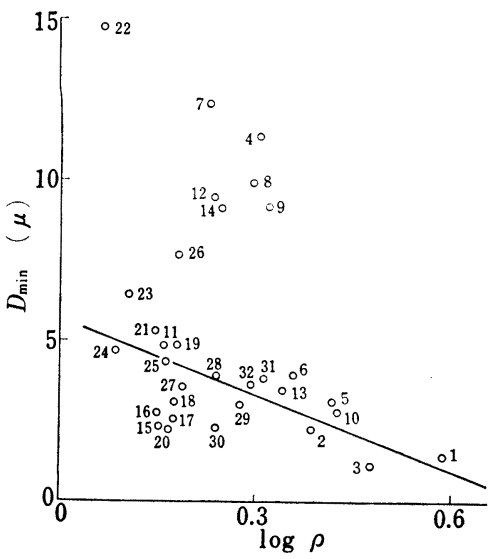

Fig. 13. Influence of True Density on Minimum Particle Diameter Obtained by Ball-Milling Powders

numbering: See Table I. 